Artigo Original

Original Article

Caroline Rodrigues Portalete ${ }^{1}$

Eduarda Giovelli Fernandes ${ }^{1}$

Karina Carlesso Pagliarin ${ }^{1}$

Descritores

Avaliação

Fala

Articulação

Adultos

Keywords

Assessment

Speech

Articulation

Adults

Endereço para correspondência:

Caroline Rodrigues Portalete

Universidade Federal de Santa Maria

- UFSM

Av. Roraima, $\mathrm{n}^{\circ} 1000$, Prédio 26 - CCS, $4^{\circ}$ andar, Sala 1418, Camobi, Santa

Maria (RS), Brasil, CEP: 97105-900.

E-mail: cportalete@gmail.com

Recebido em: Março 07, 2017

\section{Elaboração de um Protocolo de Avaliação Instrumental da Fala (PRAINF) baseado em critérios linguísticos e psicométricos}

\author{
Preparation of a Protocol for Instrumental \\ Assessment of Speech (PRAINF) based on \\ psychometric and linguistic criteria
}

\section{RESUMO}

Objetivo: Propor um protocolo para avaliação instrumental da fala de adultos, considerando critérios linguísticos e psicométricos. Método: A escolha das palavras para compor o protocolo foi baseada em critérios linguísticos do Português Brasileiro (PB), previamente definidos, após busca no banco de dados do Portal da Língua Portuguesa, utilizando o Vocabulário Ortográfico Português (VOP). Os critérios definidos foram em relação à classe gramatical, ao contexto vocálico, ao número de sílabas, à tonicidade e à presença das palavras no cotidiano dos adultos brasileiros. A escolha das figuras para representarem as palavras levou em consideração os critérios de imageabilidade, clareza da figura e aspectos culturais da imagem. Resultados: $O$ instrumento foi composto por 19 palavras/figuras, prevalecendo substantivos em relação aos adjetivos, cada palavra contemplando um fonema-alvo na posição de Onset Medial, no contexto vocálico seguinte e precedente à vogal [a], trissílabas e paroxítonas. As palavras e figuras passaram por criteriosa avaliação de 13 juízes não especialistas e 6 juízes especialistas. Após a fase de apreciação pelos juízes, as palavras foram testadas em adultos mediante avaliação instrumental. Os adultos que realizaram as avaliações instrumentais conseguiram produzir a lista de palavras espontaneamente, e os dados obtidos através das avaliações possibilitaram adequada análise. Conclusão: Este estudo forneceu informações a respeito de critérios psicométricos e linguísticos, e disponibilizou um protocolo para avaliação instrumental de fala para adultos.
Trabalho realizado na Universidade Federal de Santa Maria - UFSM - Santa Maria (RS), Brasil.

${ }^{1}$ Universidade Federal de Santa Maria - UFSM - Santa Maria (RS), Brasil.

Conflito de interesses: nada a declarar.

Fonte de financiamento: nada a declarar. 


\section{INTRODUÇÃO}

A inteligibilidade da fala é uma variável importante na comunicação oral, sendo necessário caracterizar todos os níveis envolvidos nesse processo, os quais são responsáveis pela produção correta e inteligível dos sons. Existem cinco níveis principais: ressonância, articulação, fonação, respiração e prosódia ${ }^{(1)}$. Alterações em quaisquer desses níveis podem comprometer a inteligibilidade de fala, caracterizando desvios ou distúrbios fonéticos, disfonias, disartrofonias/disartrias, etc.

Nesses casos, pessoas que apresentam alterações na produção de fala são encaminhadas para avaliação e tratamento fonoaudiológico. Porém, são escassos os instrumentos padronizados de avaliação direcionados para o público adulto ${ }^{(2,3)}$, especialmente instrumentos com critérios linguísticos, psicométricos e que possibilitem a obtenção de resultados quantitativos.

Em relação ao público adulto, os principais instrumentos para avaliação perceptiva de fala são: o Teste de Inteligibilidade de Sentença (SIT) $)^{(4)}$, o Protocolo de Avaliação das Disartrias ${ }^{(3)}$, o Protocolo de Avaliação da Inteligibilidade da Fala nas Disartrias - PAIF ${ }^{(5,6)}$ e o Protocolo da Apraxia Verbal e Não Verbal ${ }^{(7)}$.

Além das avaliações perceptivas de fala, atualmente existem avaliações instrumentais quantitativas, como a ultrassonografia de fala e a nasometria, entre outras, que permitem ao clínico identificar cada nível de produção de fala e obter parâmetros confiáveis a respeito dos níveis envolvidos na produção da fala ${ }^{(8)}$.

Portanto, para favorecer a interpretação de diversos distúrbios de fala, bem como aprimorar o diagnóstico e o processo terapêutico, é sensato aliar métodos qualitativos e quantitativos, ou seja, avaliações perceptivas e instrumentais, na análise da produção de fala.

$\mathrm{O}$ uso de instrumentos para a avaliação fonoaudiológica, como a ultrassonografia de fala, permite ao clínico a análise articulatória sincronizada aos sinais acústicos da produção( ${ }^{(9)}$. Além disso, esses instrumentos também podem servir como recursos terapêuticos na forma de biofeedbacks ao paciente, aperfeiçoando e acelerando a eficácia na reabilitação ${ }^{(10)}$.

Além desta técnica, existem outras avaliações quantitativas da fala, como Radiografia, Ressonância Magnética, Articulografia Eletromagnética, entre outros. Existem, ainda, técnicas para análise da ressonância, como a nasometria, a técnica fluxo-pressão, rinometria acústica e rinomanometria, nasofaringoscopia e videofluoroscopia $^{(11)}$.

A nasometria permite estimar a ressonância da fala, por meio da medida da nasalância, uma grandeza física que reflete a quantidade relativa de energia acústica nasal durante a fala ${ }^{(12)}$. O feedback visual durante a terapia de fala também tem se mostrado como uma alternativa de aplicação de instrumentos como a eletropalatografia, a nasometria, a ultrassonografia, entre outros, os quais vêm apresentando resultados positivos no atendimento a diversas alterações de fala ${ }^{(13)}$.

$\mathrm{O}$ uso destes recursos instrumentais em adultos necessita de um protocolo específico que permita análise pormenorizada da produção dos sons da fala. Para tanto, a escolha de palavras para compor tal protocolo deve levar em consideração critérios linguísticos específicos como contexto fonético-fonológico, além da necessidade de verificar o contexto prosódico de ocorrências dessas palavras.
Desta forma, este trabalho tem como objetivo elaborar e disponibilizar um protocolo para avaliação instrumental quantitativa da fala de adultos com base em critérios linguísticos e psicométricos, contemplando todos os fonemas consonantais do Português Brasileiro (PB), e servindo como um protocolo para análise instrumental.

\section{MÉTODO}

Esta pesquisa foi aprovada pelo Comitê de Ética em Pesquisa (CEP/UFSM), sob n ${ }^{\circ}$ 1.316.911. O estudo apenas foi realizado mediante assinatura do Termo de Consentimento Livre e Esclarecido - TCLE, em que os indivíduos concordaram com sua participação, tendo ciência de seus riscos, benefícios e do objetivo desta pesquisa. Este estudo foi realizado conforme as diretrizes e normas regulamentadoras de pesquisas envolvendo seres humanos que determina o Conselho Nacional de Saúde em sua resolução 466/12.

A criação do protocolo iniciou através da seleção das palavras, da escolha da frase-veículo e da padronização das instruções das avaliações instrumentais.

Conforme exposto na Figura 1, primeiramente foi realizada uma busca de palavras na base de dados do Portal da Língua Portuguesa, cujas consoantes-alvo deveriam estar na posição de Onset Medial (OM), entre a vogal [a]. A partir desse resultado, foram aplicados os seguintes critérios linguísticos: palavras trissilábicas, paroxítonas, excluindo-se palavras compostas por duas consoantes idênticas (uma consoante igual à consoante-alvo, exemplo: [ma.'ka.ko].

Em relação ao contexto fonético-fonológico destas palavras, o contexto vocálico e o contexto consonantal em que o fonema está inserido, bem como os segmentos consonantais adjacentes, também foram considerados, na medida em que coarticulações antecipatórias estão presentes na produção da fala ${ }^{(14,15)}$.

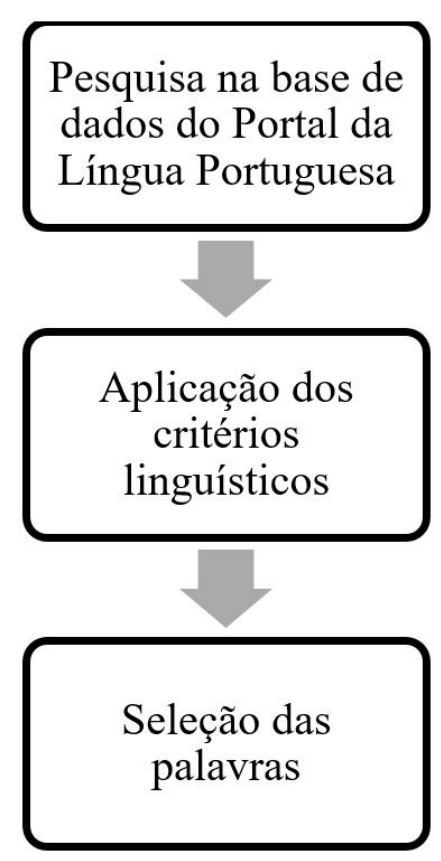

Figura 1. Descrição geral do processo de seleção das palavras 
Após a aplicação desses critérios, a escolha das palavras levou em consideração a ocorrência dos vocábulos do cotidiano dos adultos, excluindo vocábulos que pudessem ter conotação pejorativa ou ofensiva.

Para facilitar a nomeação espontânea, as palavras selecionadas deveriam ser representadas por figuras, as quais foram escolhidas levando em consideração três fatores: correspondência da figura com a imageabilidade da palavra, ou seja, a imagem mental criada pelo falante para cada palavra/conceito; a clareza da figura, de forma que a figura fosse autoexplicativa e a palavra-alvo estivesse em evidência; por fim, a familiarização das figuras com a cultura brasileira, a fim de facilitar a denominação consensual entre os falantes ${ }^{(16)}$.

O processo de seleção das palavras, figuras e da avaliação da adequação está representado na Figura 2.

Após a escolha das figuras, houve a avaliação da adequação de palavras e figuras por parte de juízes especialistas e não especialistas. A avaliação da correspondência entre palavra e figura foi feita por treze juízas não especialistas escolhidas por conveniência. Todas as juízas eram acadêmicas do quarto semestre do curso de graduação em Fonoaudiologia e já tinham experiência teórica em motricidade orofacial.

As juízas receberam uma lista com várias figuras dispostas numa tabela e deveriam nomear cada figura com a respectiva palavra. Todas as juízas foram esclarecidas quanto ao objetivo da pesquisa, bem como foram igualmente orientadas para considerarem os critérios linguísticos das palavras no momento da nomeação das figuras.

Após esta análise, as figuras e as palavras selecionadas passaram por uma criteriosa avaliação de três juízas especialistas: fonoaudiólogas especialistas em voz, em linguagem e em motricidade oral, com atuação em distúrbios motores da fala. Para cada palavra correspondente ao fonema-alvo, a juíza deveria apontar qual das alternativas era a mais adequada para a realização da coleta dos dados de fala. Em caso de apenas uma única alternativa, deveria responder apenas se a palavra e a figura eram adequadas para a coleta ou não, sugerindo reformulações caso fosse necessário.

Para a avaliação das palavras e das figuras, deveriam ser levados em consideração os critérios linguísticos e os fatores de imageabilidade, clareza da figura e aspectos culturais da imagem, ou seja, o nível de dificuldade em eliciar as palavras-alvo através da visualização das figuras.

Para participar da etapa final da elaboração do protocolo, foram escolhidas três fonoaudiólogas doutoras com experiência em elaboração de instrumentos de avaliação e terapia de fala utilizando figuras. Desta forma, as juízas deveriam apontar qual das figuras era a alternativa mais adequada para nomeação espontânea da palavra-alvo.

A fim de verificar se os estímulos escolhidos eram adequados, numa situação real de avaliação, foram convidados 10 indivíduos sem distúrbios de comunicação de ambos os gêneros, falantes típicos do PB, para realização das avaliações instrumentais quantitativas. Todos foram submetidos a uma avaliação fonoaudiológica inicial, para averiguar os aspectos de fala, voz, motricidade orofacial e audição; e a duas avaliações instrumentais: nasometria e ultrassonografia.

Para cada avaliação instrumental quantitativa, os voluntários deveriam reproduzir a lista de palavras, realizando 5 repetições para cada palavra, buscando maior fidedignidade e consistência das produções. As palavras estavam inseridas em uma frase-veículo: "Fale [palavra-alvo] de novo", para manter as palavras no mesmo contexto prosódico e fonético, evitando possíveis modificações nos parâmetros acústicos.

Considerando que a forma mais fidedigna de obtenção das amostras de fala é a nomeação espontânea, foram apresentadas figuras na tela do computador para que o adulto falasse espontaneamente a palavra-alvo durante as avaliações instrumentais quantitativas, eliminando o viés da repetição (estímulo auditivo) e da leitura (palavra escrita).

Numa situação de avaliação instrumental da nasalância, utilizando a Nasometria, através do software Nasometer $I I^{(17)}$, a seguinte ordem foi dada: "Você visualizará algumas imagens no monitor que está à sua frente, para cada imagem você deverá reproduzir cinco vezes a seguinte frase 'Fale [o nome da figura] de novo'. Por exemplo, se você visualizar a figura de um cavalo, deverá reproduzir a frase "Fale cavalo de novo"'.

Numa situação de avaliação instrumental da articulação, utilizando a Ultrassonografia através do software Articulate Assistant Advanced ${ }^{(18)}$, a seguinte ordem foi dada: "Você visualizará algumas imagens no monitor que está à sua frente, para cada imagem você deverá reproduzir a seguinte frase 'Fale [o nome da figura] de novo'. Por exemplo, se você visualizar a figura de um cavalo, deverá reproduzir a frase 'Fale cavalo de novo'. As figuras serão apresentadas de maneira aleatória, portanto, após o término da primeira reprodução de todas as palavras, o procedimento será repetido mais quatro vezes".

Para participarem das avaliações instrumentais quantitativas, os adultos voluntários deveriam estar de acordo com os seguintes critérios estabelecidos: ter nascido e/ou sido criado em Santa

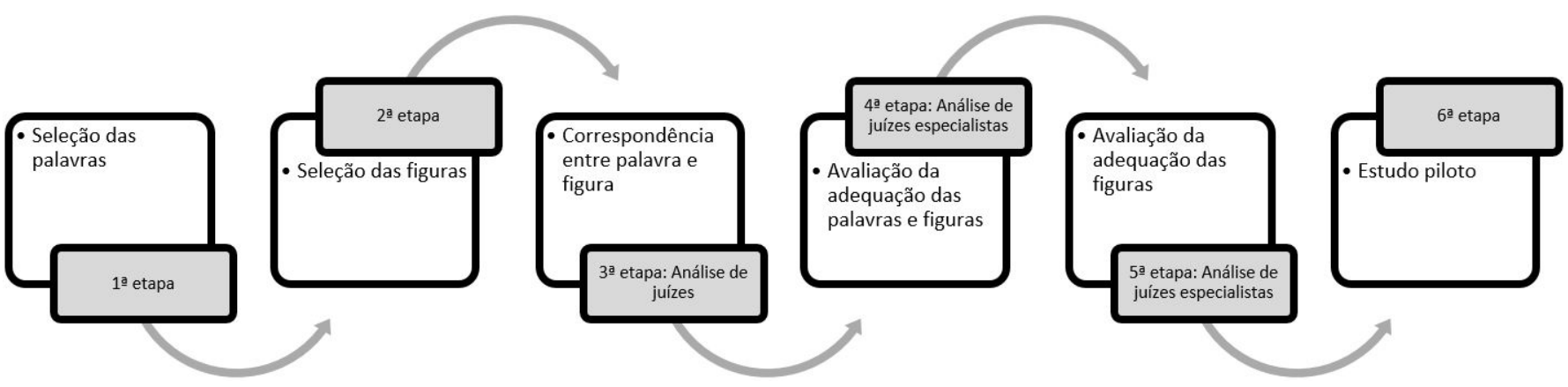

Figura 2. Descrição geral do processo de análise das palavras selecionadas 
Maria/RS; possuir idade entre 19:00 e 44:11 (idade determinada pela OMS para classificar adultos jovens); ter todas as avaliações fonoaudiológicas dentro dos padrões de normalidade (adequada linguagem compreensiva e expressiva oral, estruturas e funções orofaciais adequadas, voz adequada ao falante, tipo e modo respiratórios adequados e limiares auditivos dentro dos padrões de normalidade); ter laudo otorrinolaringológico normal; ter grau de nasalância inferior a $27 \%{ }^{(19)}$.

Os adultos seriam excluídos caso relatassem queixas quanto à fala, voz e/ou audição; apresentassem alterações de linguagem; já tivessem realizado terapia fonoaudiológica; tivessem histórico de alterações fonéticas e/ou fonológicas; apresentassem quadros alérgicos; usassem prótese dentária ou aparelho dentário fixo ou móvel; fossem portadores de necessidades especiais e, por exemplo, utilizassem cadeira de rodas; fossem usuários de medicamentos controlados, álcool, tabaco e drogas ilícitas; apresentassem quadro neurológico ou psiquiátrico.

A pesquisa constituiu-se por avaliações fonoaudiológicas iniciais para seleção do grupo de estudo e avaliações instrumentais quantitativas (Ultrassonografia e Nasometria) para coleta de dados.

Para verificar a adequação da correspondência entre palavra e figura, utilizou-se o método de "Porcentagem de Concordância".

$$
\% \text { concordância }=\frac{\begin{array}{c}
\text { número de participantes } \\
\text { que concordaram }
\end{array}}{\begin{array}{c}
\text { número total de } \\
\text { participantes }
\end{array}} \times 100
$$

A fim de medir a proporção de concordância de respostas entre os juízes especialistas, foi utilizado o cálculo do Índice de Validade de Conteúdo.

$I V C=\frac{\text { número de respostas " } 3 \text { " ou " } 4 \text { " }}{\text { número total de respostas }}$

Sendo 3 bastante claro e 4 muito claro.

\section{RESULTADOS}

A Tabela 1 representa os resultados iniciais da pesquisa na base de dados do Portal da Língua Portuguesa. Os vocábulos foram pesquisados em relação ao contexto vocálico, à posição do fonema, ao fonema consonantal na posição de Onset Medial e à classe gramatical: substantivos ou adjetivos.

A seleção dessas palavras após a aplicação dos critérios linguísticos levou em consideração a frequência do vocábulo no cotidiano dos adultos e a possibilidade de representação por figuras. Algumas palavras, como "sacada", "casados", "machado", "cajado" e "banhado" foram as únicas que se encaixaram nos critérios linguísticos para o fonema-alvo em questão.

A partir desta seleção, juízas não especialistas foram solicitadas a informar a correspondência entre palavra e figura, conforme exposto no Quadro 1.

A avaliação da correspondência entre figuras e palavras deu-se através de uma lista de figuras, na qual as juízas não especialistas deveriam nomear a figura, de acordo com o Quadro 2. Os resultados foram analisados conforme "Porcentagem de Concordância", por ser uma medida mais simples de concordância entre juízes e interobservadores na fase inicial da pesquisa ${ }^{(20)}$.
A taxa aceitável de concordância é acima de $90 \%$ e não deve ser inferior a $78 \%$ entre os avaliadores ${ }^{(21)}$.

Observa-se nesse quadro que, das 44 palavras avaliadas, os vocábulos com concordância acima de $78 \%$ totalizaram 19 vocábulos $(43,18 \%)$. Os acertos acima de 90\% totalizaram 11 vocábulos (25\%), sendo que houve $100 \%$ de respostas corretas para apenas 8 vocábulos (18,18\%). Tendo em vista que houve vocábulos em que não houve adequada concordância entre as juízas, foi realizada uma nova verificação da adequação dos vocábulos com juízas especialistas.

Tabela 1. Resultados quantitativos dos vocábulos existentes na base de dados do Portal da Língua Portuguesa, observando os critérios linguísticos adotados

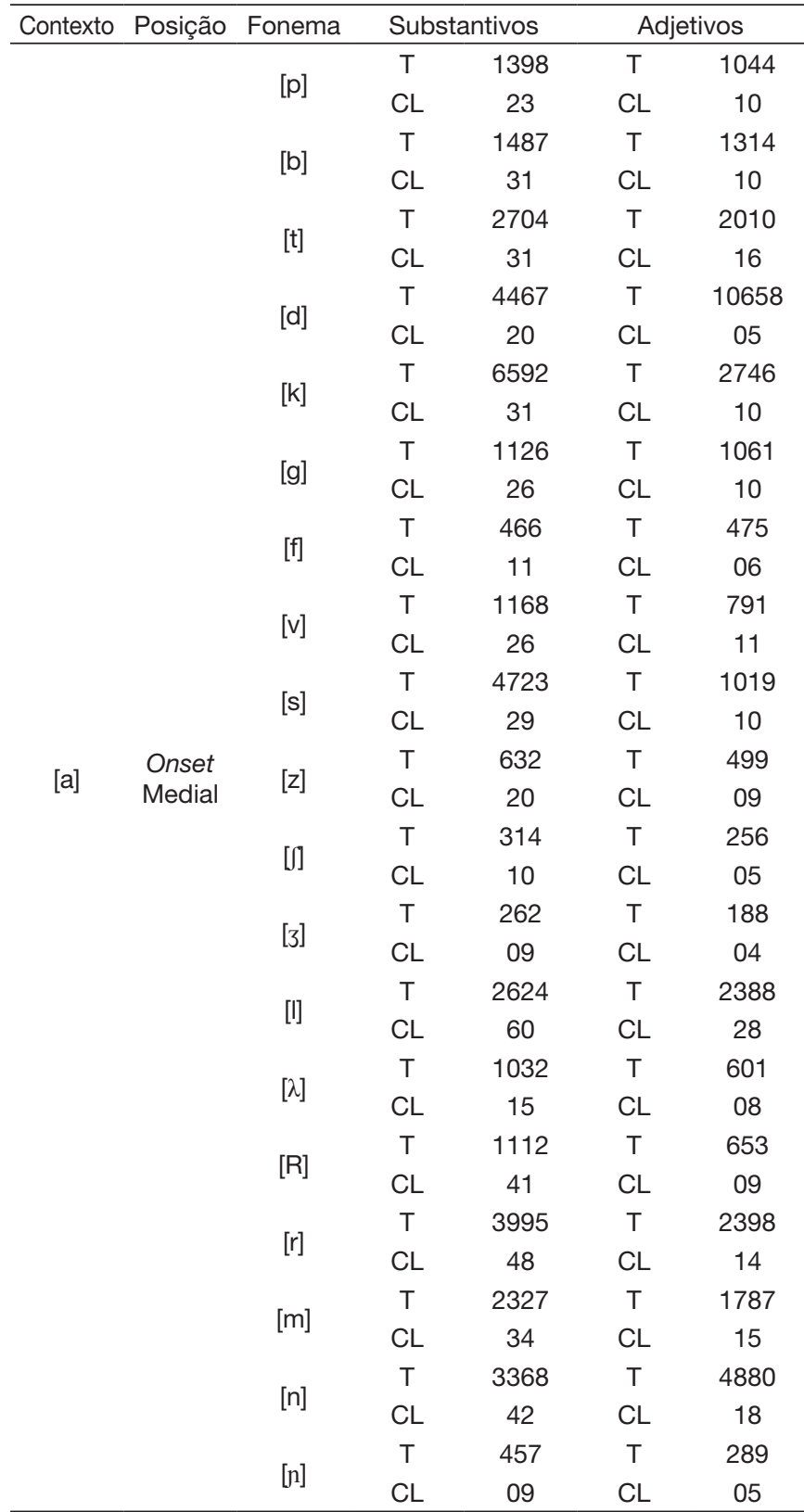

Legenda: $\mathrm{T}$ = total de vocábulos encontrados*; $\mathrm{CL}=$ vocábulos encontrados com os critérios linguísticos. *Consideraram-se vocábulos tanto no singular quanto no plural, bem como de qualquer gênero (feminino, masculino e neutro). 
Quadro 1. Lista de palavras selecionadas após aplicação dos critérios linguísticos para avaliação de juízas especialistas e não especialistas

\begin{tabular}{|c|c|c|c|c|c|}
\hline Fonema-alvo & Palavra & Transcrição & Fonema-alvo & Palavra & Transcrição \\
\hline \multirow{3}{*}{$/ p /$} & Sapato & [sa.'pa.to] & \multirow{3}{*}{$/ \int /$} & \multirow{3}{*}{ Machado } & \multirow{3}{*}{ [ma.'Ja.do] } \\
\hline & Tapado & [ta.'pa.do] & & & \\
\hline & Chapada & [ a.'pa.de] & & & \\
\hline \multirow{3}{*}{ /b/ } & Tabaco & [ta.'ba.ko] & \multirow{3}{*}{ /3/ } & \multirow{3}{*}{ Cajado } & \multirow{3}{*}{ [ka. 'Za.do] } \\
\hline & Abaixo & [a.'baj.Jo] & & & \\
\hline & Cabala & [ka.'ba.le] & & & \\
\hline \multirow{3}{*}{$/ t /$} & Batalha & [ba.'ta.Ke] & \multirow{3}{*}{ /I/ } & Salada & [sa.'la.da] \\
\hline & Atado & [a.'ta.do] & & Palácio & [pa.'la.sio] \\
\hline & Ataque & [a.'ta.ke] & & Balada & [ba.'la.de] \\
\hline \multirow{3}{*}{ /d/ } & Cadarço & [ka.'dar.so] & \multirow{3}{*}{$/ \Lambda /$} & Palhaço & [pa. 'אa.so] \\
\hline & Adaga & [a.'da.ge] & & Malhada & [ma.'Ka.de] \\
\hline & & & & Palhada & [pa.'Ka.de] \\
\hline \multirow{3}{*}{$/ \mathbf{k} /$} & \multirow{3}{*}{ Sacada } & \multirow{3}{*}{ [sa.'ka.da] } & \multirow{3}{*}{$/ \mathbf{r} /$} & Barata & [ba.'ra.ta] \\
\hline & & & & Baralho & [ba.'ra.রo] \\
\hline & & & & Parada & [pa.'ra.de] \\
\hline \multirow{3}{*}{$/ g /$} & Bagagem & [ba.'ga.zej] & \multirow{3}{*}{ /R/ } & \multirow{3}{*}{ Barraca } & \multirow{3}{*}{ [ba.'Ra. ke] } \\
\hline & Lagarto & [la.'gar.to] & & & \\
\hline & Bagaço & [ba.'ga.so] & & & \\
\hline \multirow{3}{*}{$/ \mathbf{f} /$} & Mafalda & [ma.'faw.de] & \multirow{3}{*}{$/ \mathrm{m} /$} & Damasco & [da.'mas.ko] \\
\hline & Safari & [sa.'fa.ri] & & ChamadaCamaro & [ a.'ma.de] \\
\hline & Afago & [a.'fa.go] & & & [ka.'ma.ro] \\
\hline \multirow{3}{*}{$/ \mathbf{v} /$} & Cavalo & [ka.'va.lo] & \multirow{3}{*}{ /n/ } & Canário & [ka.'na.rio] \\
\hline & Lavabo & [la.'va.bo] & & GranadaManada & [gra.'na.da] \\
\hline & Navalha & [na.'va. Ke] & & & [ma.'na.de] \\
\hline \multirow{3}{*}{ /s/ } & Passagem & [pa.'sa. zej] & \multirow{3}{*}{$/ \mathrm{y} /$} & \multirow{3}{*}{ Banhado } & \multirow{3}{*}{ [bã.'ya.do] } \\
\hline & Massagem & [ma.'as. 3ej] & & & \\
\hline & Caçada & [ka.'sa.de] & & & \\
\hline /z/ & Casados & [ka.'za.dos] & & & \\
\hline
\end{tabular}

Quadro 2. Resultado das respostas em relação à correspondência entre palavra e figura por juízas não especialistas

\begin{tabular}{|c|c|c|c|c|c|c|}
\hline Fonema-alvo & Palavra 1 & $\%$ & Palavra 2 & $\%$ & Palavra 3 & $\%$ \\
\hline [p] & Sapato & 100 & Tapado & 16,67 & Chapado & 0 \\
\hline [b] & Tabaco & 25 & Abaixo & 0 & Cabala & 0 \\
\hline [d] & Cadarço & 100 & Adaga & 0 & - & - \\
\hline$[\mathrm{k}]$ & Sacada & 100 & - & - & - & - \\
\hline [g] & Bagagem & 25 & Lagarto & 75 & Bagaço & 41,67 \\
\hline$[\mathrm{V}]$ & Cavalo & 83,3 & Lavabo & 25 & Navalha & 41,67 \\
\hline$[\mathrm{s}]$ & Passagem & 33,3 & Massagem & 100 & Caçada & 58,3 \\
\hline [z] & Casados & 41,67 & - & - & - & - \\
\hline$\left[\int\right]$ & Machado & 91,67 & - & - & - & - \\
\hline [3] & Cajado & 50 & - & - & - & - \\
\hline$[\mathrm{R}]$ & Barraca & 91,67 & - & - & - & - \\
\hline [m] & Damasco & 41,67 & Chamada & 41,67 & Camaro & 83,3 \\
\hline$[\mathrm{n}]$ & Canário & 58,3 & Granada & 86,67 & Manada & 86,67 \\
\hline [n] & Banhado & 0 & - & - & - & - \\
\hline
\end{tabular}


Nessa fase, juízas especialistas indicaram qual/se a palavra era adequada ou não ao item (fonema-alvo) através do Índice de Validade de Conteúdo (IVC), cujos resultados estão apresentados na Tabela 2. Não foram admitidas notas 1 ou 2 (pouco claras ou não claras), caracterizando automaticamente exclusão do vocábulo.

Desta forma, 11 vocábulos foram considerados muito claros para o fonema-alvo, e 8 vocábulos considerados bastante claros. Sendo assim, elaborou-se a lista de palavras para contemplar todos os fonemas-alvo, conforme Quadro 3.

No intuito de verificar a adequação das imagens para representar as palavras, foi realizada nova avaliação por outras juízas especialistas. A partir das respostas, elaborou-se a seguinte lista de figuras, expostas no Quadro 4.
Tabela 2. IVC entre juízas especialistas

\begin{tabular}{ccc}
\hline & IVC Nota 3 & Nota 4 \\
\hline Tabaco & Sapato \\
Atado & Cadarço \\
Safari & Sacada \\
Damasco & Lagarto \\
Galavra-alvo & Cavalo \\
& Banhado & Massagem \\
& Machado \\
& Salada \\
& Palhaço \\
\end{tabular}

Quadro 3. Lista de palavras do Protocolo de Avaliação Instrumental de Fala

\begin{tabular}{|c|c|c|c|c|c|}
\hline Fonema-alvo & Palavra & Transcrição & Fonema-alvo & Palavra & Transcrição \\
\hline$/ \mathrm{p} /$ & Sapato & [sa.'pa.tu] & $/[/$ & Machado & [ma.'Ja.du] \\
\hline$/ \mathrm{b} /$ & Tabaco & [ta.'ba.ku] & /3/ & Cajado & [ka. '3a.du] \\
\hline$/ \mathrm{t} /$ & Atado & [a.'ta.du] & /I/ & Salada & [sa.'la.de] \\
\hline$/ \mathrm{d} /$ & Cadarço & [ka.'dar.su] & $I K I$ & Palhaço & [pa. 'Ka.su] \\
\hline$/ \mathbf{k} /$ & Sacada & [sa.'ka.de] & $/ \mathbf{r} /$ & Barata & [ba.'ra.te] \\
\hline$/ g /$ & Lagarto & [la.'gar.tu] & /R/ & Barraca & [ba.'Ra. ke] \\
\hline$/ \mathrm{f} /$ & Safari & [sa.'fa.ri] & $/ \mathrm{m} /$ & Damasco & [da.'mas.ku \\
\hline$/ v /$ & Cavalo & [ka.'va.lu] & $/ \mathrm{n} /$ & Granada & [gra.'na.de] \\
\hline$/ \mathrm{s} /$ & Massagem & [ma.'sa. 3ẽj] & $/ \mathrm{n} /$ & Banhado & [bã.'ya.du] \\
\hline$/ z /$ & Casados & [ka.'za.dus] & & & \\
\hline
\end{tabular}

Quadro 4. Lista de figuras do Protocolo de Avaliação Instrumental de Fala

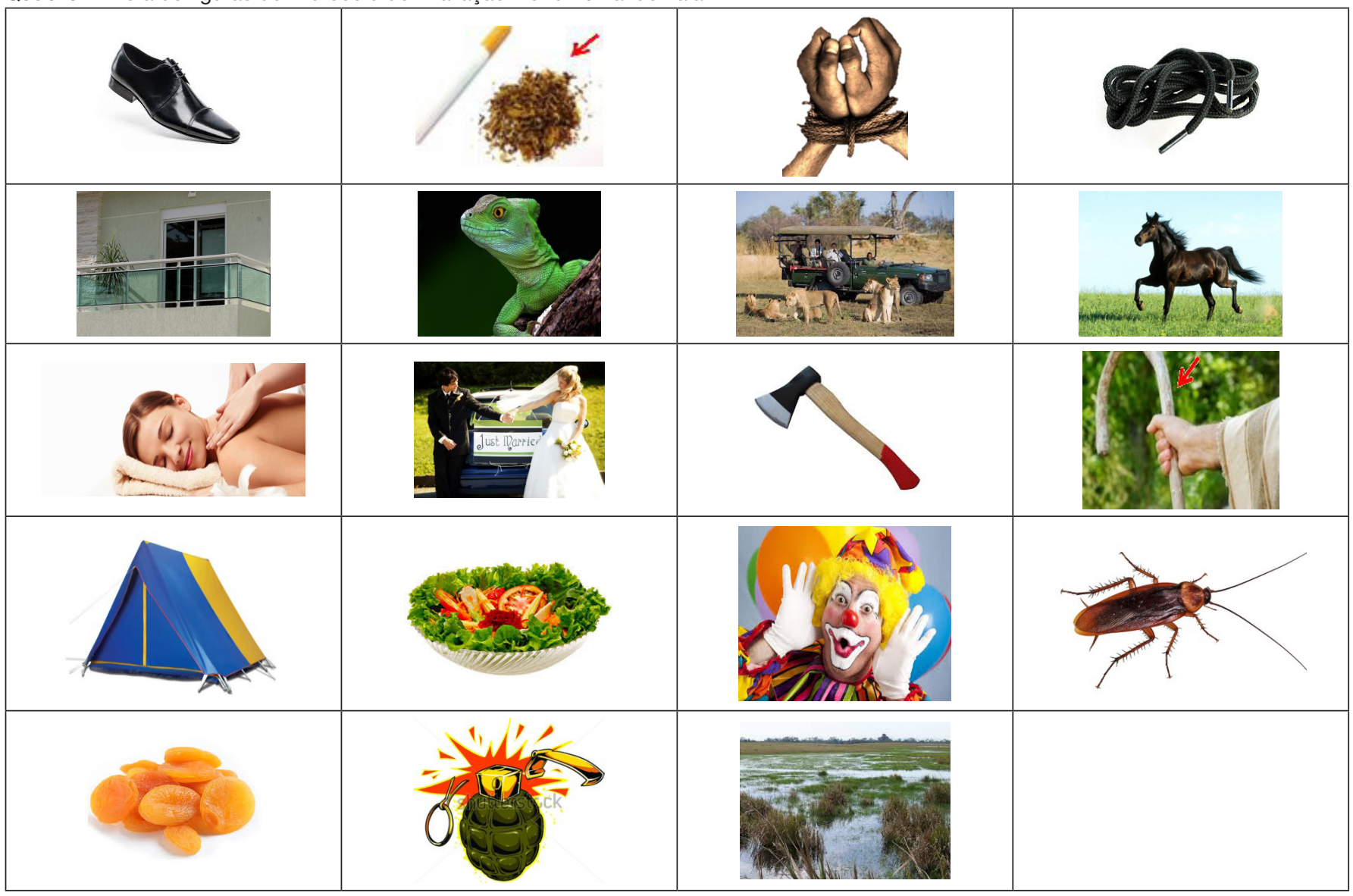




\section{DISCUSSÃO}

O PRAINF foi composto por 19 palavras, cada uma contemplando uma consoante do Português Brasileiro. A pesquisa inicial das palavras deu-se através do Vocabulário Ortográfico Português (VOP), integrado ao Portal da Língua Portuguesa. O VOP é composto por cerca de 318000 verbetes e tem como base o Vocabulário da Língua Portuguesa ${ }^{(22)}$.

As palavras foram selecionadas considerando os seguintes critérios linguísticos: fonema-alvo na posição de Onset Medial, entre a vogal [a], em palavras trissílabas e paroxítonas, conforme indicado em estudo anterior ${ }^{(16)}$, a fim de garantir uma padronização para as análises comparativas posteriores.

Optou-se por escolher palavras trissílabas em virtude da facilidade em encontrar vocábulos com consoante em OM, entre a vogal [a], em paroxítonas ${ }^{(15,23)}$. Em estudo anterior ${ }^{(23)}$, através do exame de um corpus geral de 150875 palavras, constatou que $24,9 \%$ eram oxítonas, $62,5 \%$ paroxítonas e $12,2 \%$ proparoxítonas, corroborando com a afirmação de que as paroxítonas são o padrão de acentuação mais frequente do português.

Ademais, a posição dos fonemas em OM foi escolhida devido a não ocorrência do fonema [r] em Onset Inicial no PB. Tendo em vista a aplicação do protocolo em diversas avaliações instrumentais, incluindo a ultrassonografia de fala, escolheu-se analisar o fonema em sílaba tônica, pois a amplitude do movimento da língua nesse contexto é maior e, por isso, fornece uma imagem ultrassonográfica melhor ${ }^{(24)}$.

A não ocorrência de duas consoantes iguais na mesma palavra, sendo uma a consoante-alvo, serve para evitar efeitos de coarticulação. À luz da Fonologia Autossegmental, o efeito de coarticulação existe pela interação consoante-consoante, a qual gera consoantes em sequência que passam a compartilhar o mesmo ponto de articulação. A interação consoante-consoante pode ser evidenciada, por exemplo, ao verificar que consoantes palatais favorecem a palatalização de plosivas coronais ${ }^{(25)}$.

Esse modelo teórico é representado pela interligação de estruturas melódicas, em decorrência do princípio conhecido como OCP (Obligatory Contour Principle/Princípio do Contorno Obrigatório), que proíbe elementos adjacentes iguais, causando ou o desligamento de um desses elementos ou o reconhecimento de sua unidade pela interligação dos elementos idênticos ${ }^{(26)}$.

Em relação à correspondência entre palavra e figura, 13 figuras tinham correspondência direta à palavra (exemplo: a palavra sapato foi representada por um sapato), enquanto que 6 correspondiam indiretamente (exemplo: a palavra massagem foi representada por uma mulher recebendo uma massagem).

As palavras que não puderam ser representadas diretamente pelas figuras e necessitavam de interpretação/dedução por parte do paciente foram mantidas devido aos critérios linguísticos definidos e pela inexistência de palavra alternativa.

Em situações em que algumas palavras não foram nomeadas adequadamente, $\mathrm{o}$ avaliador mostrou a palavra escrita abaixo da figura-alvo apenas naquele momento, supondo que nas próximas repetições a palavra seria nomeada corretamente.
Para assegurar a nomeação da palavra corretamente, todos os estímulos são demonstrados para o participante juntamente com a palavra escrita antes do início da coleta.

Foram realizadas avaliações da adequação das palavras por juízes especialistas e não especialistas no intuito de verificar a validade deste protocolo na coleta de dados de fala. A validade de conteúdo compreende, além de uma avaliação por parte de especialistas, o processo de desenvolvimento do protocolo, sendo avaliada por meio de procedimentos qualitativos e quantitativos ${ }^{(26)}$. Pode-se considerar um instrumento válido quando ele consegue avaliar realmente seu objetivo, nesse caso, a obtenção de dados de fala envolvidos na articulação e na nasalância.

Privilegiou-se a coleta de dados através da nomeação/fala espontânea por haver maior correspondência com a fala e fluência natural, em virtude do planejamento motor, execução do movimento e processamento linguístico, o que não ocorre na coleta de dados de fala através da leitura oral ou repetição ${ }^{(27,28)}$. Além disso, as coletas através da leitura oral ou repetição superestimam a inteligibilidade conversacional em alguns pacientes, alterando o resultado da avaliação da função comunicativa ${ }^{(2)}$.

As palavras estavam inseridas em uma frase-veículo a fim de manter um contexto prosódico e dar mais naturalidade à produção da palavra ${ }^{(29)}$. Salienta-se que para escolha dos vocábulos consideraram-se fatores como a familiaridade com o vocabulário e a extensão da palavra, que favorecem a inteligibilidade de fala por conta da habilidade de fechamento auditivo $^{(30)}$. Desta forma, a avaliação da fala restringe-se apenas aos seus componentes acústicos.

Estudos apontam para a necessidade do uso de frase-veículo para análise em vez de palavras isoladas, também para obter maior controle da estrutura prosódica das sentenças, para que assim a produção seja adequada ${ }^{(15)}$. As limitações deste estudo incluem a impossibilidade de investigar todas as palavras do Português Brasileiro, em razão da inexistência de uma plataforma on-line com acesso a todos os vocábulos. Ademais, salienta-se que o estudo foi realizado com poucas pessoas e ainda está em fase de verificação da confiabilidade ${ }^{(26)}$.

\section{CONCLUSÃO}

Os resultados do presente trabalho trazem benefícios não apenas para a comunidade acadêmica, como também para a clínica fonoaudiológica, pois até o momento havia carência de um protocolo de avaliação de produção e/ou percepção de fala, ainda mais considerando metodologias de padronização de critérios linguísticos para a avaliação instrumental da fala de pacientes adultos.

É imprescindível que se tenha cautela no momento da coleta, pois os parâmetros de ordem linguística (como sotaque, contexto vocálico, tonicidade, padrão silábico, etc.) causam impactos na produção da fala. Salienta-se, ainda, que a fidedignidade da avaliação leva em consideração a correta aplicação do protocolo, desde a padronização das instruções, apresentação dos estímulos ao falante, produção correta pelo falante e até a interpretação dos resultados pelo avaliador. Sendo assim, o protocolo criado neste estudo é adequado para ser utilizado na coleta de dados relativos à produção de fala, viabilizando, a critério do avaliador, a análise instrumental da fala. 


\section{REFERÊNCIAS}

1. Ortiz KZ. Distúrbios neurológicos adquiridos: fala e deglutição. 2. ed. Baurueri: Manole; 2010.

2. Barreto SS. Protocolo de avaliação da inteligibilidade da fala nas disartrias: evidências de fidedignidade e de validade [tese]. São Paulo: Universidade Federal de São Paulo; 2012.

3. Fracassi AS, Gatto AR, Weber S, Spadotto AA, Ribeiro PW, Schelp AO. Adaptação para a língua Portuguesa e aplicação de protocolo de avaliação das disartrias de origem central em pacientes com Doença de Parkinson. Rev CEFAC. 2010;6(13):1056-65.

4. Beukelman D, Yorkston K, Hakel M, Dorsey M. Speech intelligibility test. Lincoln: Madonna Rehabilitation Hospital; 2007.

5. Barreto SS, Ortiz KZ. Protocol for the evaluation of speech intelligibility in dysarthrias: evidence of reliability and validity. Folia Phoniatr Logop. 2015;67(4):212-8. http://dx.doi.org/10.1159/000441929. PMid:26771521.

6. Alexandre E, Barreto SS, Ortiz KZ. Preditividade das sentenças do protocolo de avaliação da inteligibilidade da fala nas disartrias. J Soc Bras Fonoaudiol. 2011;23(2):119-23. http://dx.doi.org/10.1590/S2179-64912011000200007. PMid:21829926.

7. Martins FC, Ortiz KZ. Proposta de protocolo para avaliação da apraxia de fala. Fono Atual. 2004;7(30):53-61.

8. Murdoch DE. Disartria: uma abordagem fisiológica para avaliação e tratamento. São Paulo: Lovise; 2005.

9. Zharkova N. Using ultrasound to quantify tongue shape and movement characteristics. Cleft Palate Craniofac J. 2013;50(1):76-81. http://dx.doi. org/10.1597/11-196. PMid:22117937.

10. Klein HB, Byun TM, Davidson L, Grigos MI. A multidimensional investigation of children's productions perceptual ultrasound and acoustic measures. Am J Speech Lang Pathol. 2013;22(3):540-53. http://dx.doi. org/10.1044/1058-0360(2013/12-0137). PMid:23813195.

11. Salgueiro AGNS, Silva ASC, Araújo BMAM, Yamashita RP, Trindade IEK. Análise comparativa da atividade velofaríngea aferida por rinometria acústica e rinomanometria. CoDAS. 2015;5(27):464-71. http://dx.doi. org/10.1590/2317-1782/20152015006. PMid:26648218.

12. Fukushiro AP. Análise perceptiva, nasométrica e aerodinâmica da fala de indivíduos submetidos à cirurgia de retalho faríngeo para a correção da insuficiência velofaríngea [tese]. São Paulo: Universidade de São Paulo; 2007.

13. Byun TM, Hitchcock ER, Swartz MT. Retroflex versus bunched in treatment for rhotic misarticulation: evidence for ultrasound biofeedback intervention. J Speech Lang Hear Res. 2014;57(6):2116-30. http://dx.doi. org/10.1044/2014_JSLHR-S-14-0034. PMid:25088034.

14. Marino VCC, Santos IM, Fabron EMG, Dutka JCR, Gurgel JA, Berti LC. Influência do contexto silábico da palavra no julgamento perceptivo-auditivo do ceceio produzido por pré-escolares. Rev CEFAC. 2013;15(4):922-31. http://dx.doi.org/10.1590/S1516-18462012005000102.

15. Berti LC, Pagliuso A, Lacava F. Instrumento de avaliação de fala para análise acústica (IAFAC) baseado em critérios linguísticos. Rev Soc Bras Fonoaudiol. 2009;3(14):305-14. http://dx.doi.org/10.1590/S151680342009000300005 .

16. Ishigaki ECSS, Lobrigate NL, Fonseca RP, Parente MAMP, Ortiz KZ. Análise do reconhecimento das figuras do Teste MT Beta-86 modificado para uma adaptação: descrição e discussão de aspectos metodológicos. CoDAS.
2013;25(3):282-8. http://dx.doi.org/10.1590/S2317-17822013000300015. PMid:24408341.

17. Kay Elemetrics. Nasometer II model 6400/6402: installation, operations, and maintenance manual. Lincoln Park: Kay Elemetrics; 2003.

18. Articulate Instruments LTD. Articulate assistant user guide: version: 2.11. Edinburgh: Articulate Instruments; 2010.

19. Trindade IEK, Yamashita RP, Suguimoto RM, Mazzottini R, Trindade AS Jr. Effects of orthognathic surgery on speech and breathing of subjects with cleft lip and palate: acoustic and aerodynamic assessment. Cleft Palate Craniofac J. 2003;40(1):54-64. http://dx.doi.org/10.1597/15451569(2003)040<0054:EOOSOS>2.0.CO;2. PMid:12498606.

20. Hulley SB, Cummings SR, Browner WS, Grady D, Hearst N, Newman TB. Delineando a pesquisa clínica. 2. ed. Porto Alegre: Artmed; 2003.

21. Lynn MR. Determination and quantification of content validity. Nurs Res. 1986;35(6):382-5. http://dx.doi.org/10.1097/00006199-198611000-00017. PMid:3640358.

22. Gonçalves FR. Vocabulário da Língua Portuguesa. Coimbra: Coimbra Editora; 1966.

23. Araújo GA, Guimarães-Filho ZO, Oliveira L, Viaro ME. Algumas observações sobre as proparoxítonas e o sistema acentual do português. In: Araújo G, editor. O acento em português: abordagens fonológicas. São Paulo: Parábola; 2007.

24. Barberena LS, Brasil BC, Melo RM, Mezzomo CL, Mota HB, KeskeSoares M. Ultrasound applicability in Speech Language Pathology and Audiology. Codas. 2014;26(6):520-30. http://dx.doi.org/10.1590/23171782/20142013086. PMid:25590916.

25. Matzenauer CLB. Restrições segmentais e prosódicas na aquisição das líquidas do Português Brasileiro e do Português Europeu. In: Anais do II Congresso Internacional da ABRALIN; 2001 Mar 16-18; Fortaleza. Fortaleza: Universidade Federal do Ceará; 2003.

26. Alexandre NMC, Coluci MZO. Validade de conteúdo nos processos de construção e adaptação de instrumentos de medidas. Ciência e Saúde Coletiva. 2011;16(7):3061-8. http://dx.doi.org/10.1590/S1413-81232011000800006.

27. Pinto JCBR, Schiefer AM, Avila CRB. Disfluências e velocidade de fala em produção espontânea e em leitura oral em indivíduos gagos e não gagos. ACR. 2013;18(2):63-70.

28. Fiorin M, Ugarte CV, Capellini SA, Oliveira CMC. Fluência da leitura e da fala espontânea de escolares: estudo comparativo entre gagos e não gagos. Rev CEFAC. 2015;17(1):151-8. http://dx.doi.org/10.1590/1982021620152014.

29. Nascimento KR, Carvalho WJA. Análise acústica de sons vocálicos de palavras funcionais do inglês. Revista Diadorim. 2012; 12: 189-213.

30. Jacob LCB, Alvarenga KF, Zeigelboim BS. Avaliação audiológica do sistema nervoso auditivo central. Arquivos da Fundação de Otorrinolaringologia. 2000;4(4):144-51.

\section{Contribuição dos autores}

CRP foi responsável pela delimitação do estudo, análise dos critérios linguísticos e seleção das palavras e figuras que compuseram o protocolo, e coleta dos dados; EGF auxiliou nas coletas dos dados e, conjuntamente, realizou pesquisa bibliográfica e redação do artigo; KCP supervisionou a coleta e análise dos dados, bem como, forneceu orientações durante todas as etapas de elaboração do estudo. 